\title{
Los ambientes de aprendizaje en el C.E.I.P. María Zambrano
} Learning environments at C.E.I.P. María Zambrano infant and primary public school

Lourdes Vera García ${ }^{1}$, Vidalina Pérez Marín², María Del Mar Leiva Rivas³

y Celes Monreal Palma ${ }^{4}$

Recibido: 30 de noviembre de 2019 Aceptado: 17 de diciembre de 2019 Publicado: 31 de enero de 2020

To cite this article: Vera, L., Pérez, V. y Leiva, Ma M. y Monreal, C. (2020). Los ambientes de aprendizaje en el C.E.I.P. María Zambrano. Márgenes, Revista de Educación de la Universidad de Málaga, 1 (1), 210-231

DOI: http://dx.doi.org/10.24310/mgnmar.v111.7350

\author{
${ }^{1}$ Lourdes Vera García 0000-0003-0301-79943 \\ CEIP María Zambrano (Mijas-Costa, Málaga) \\ lourvera81@gmail.com
}

2Vidalina Pérez Marín 0000-0002-2089-595

CEIP María Zambrano (Mijas-Costa, Málaga)

micolesmicasa@gmail.com

\author{
${ }^{3}$ María Del Mar Leiva Rivas \\ CEIP María Zambrano (Mijas-Costa, Málaga) \\ mmar.rivas87@gmail.com
}

\author{
${ }^{4}$ Celes Monreal Palma \\ CEIP María Zambrano (Mijas-Costa, Málaga) \\ celesmp@gmail.com
}

\section{RESUMEN}

Esta experiencia nace de la inquietud y necesidad de dejar de soñar en una escuela diferente y andar un camino cuyo proceso se relata en este artículo. Es un centro público, el C.E.I.P. María Zambrano y en la etapa de Educación Infantil, donde los encuentros, formación y ganas de las maestras/os, las ha llevado a diseñar unos espacios, ambientes de aprendizajes, que transforman todo el escenario, relaciones y roles que habitan en una escuela.

Palabras clave: educación infantil; ambientes de aprendizaje; materiales; mindfullness; diversidad; espacios; juego

\section{ABSTRACT}

This experience originated from the restlessness and need to stop dreaming of a different school and move towards a new method witch process is described in this article. It is a public school, C.E.I.P. María Zambrano and it is in the Infant school grades where the teachers meetings, learning courses and well intentions have taken them to develop spaces, learning environments that transforms all the relationships and roles that inhabit a school.

Keywords: child education; learning environments; materials; mindfullness; diversity; spaces; relations; play 


\section{TODO COMENZÓ...}

"La escuela infantil es un teatro continuo, fascinante y de gran interés, lleno de improvisaciones, de hechos, de gestos, de tramas, de comportamientos y de relaciones entre los niños. Las imágenes describen los hechos y las situaciones, narran la historia" (Hoyuelos, 2004, citado en Villarroel, 2015, p. 166).

El comienzo de esta maravillosa ex-

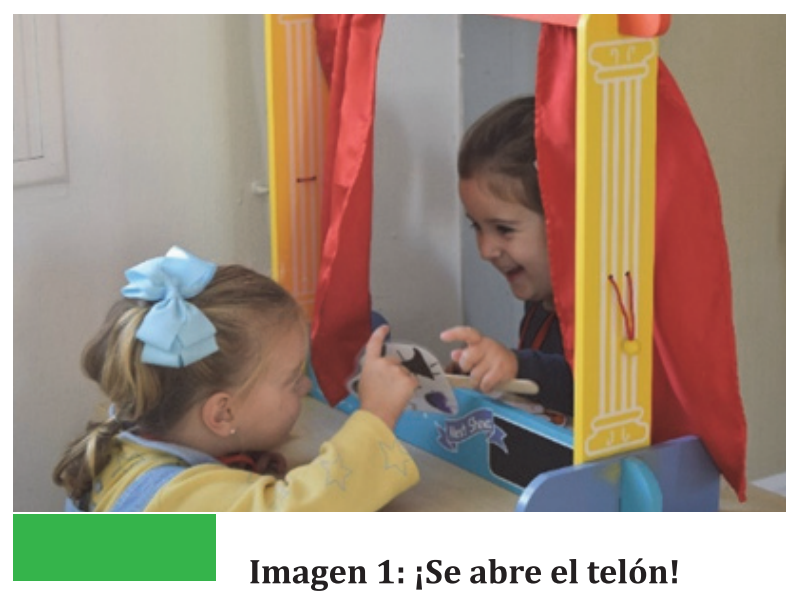
periencia proviene de las inquietudes de algunas maestras que necesitaban buscar otras formas de hacer y vivir en el aula. Tener una visión de una escuela diferente y respetuosa con el alumnado y sus procesos, ver que ésta es posible con la normativa actual, nos ha marcado un antes y un después en nuestra práctica educativa y en nuestros planteamientos teóricos; nuestra pretensión es innovar en esta etapa educativa poniendo en práctica una metodología diferente.

El visitar otros centros, como El Martinet y el centro internacional Loris Malaguzzi y escuelas de Reggio Emilia, hicieron comprobar que los cambios y procesos son posibles y nos pusimos manos a la obra.

Comenzamos el primer curso con dos unidades de cinco años, y durante el verano anterior estuvimos diseñado y planificando el sustento teórico para incorporarlo en el proyecto educativo de infantil, pero sobre todo y lo más complicado, era cambiar la organización, planificación y nuestro nuevo papel de maestras en el aula, así como rutinas asentadas en nuestras prácticas. Presentar a las familias este cambio que queríamos acometer en el último curso del ciclo de infantil suponía un choque para todos/ as, pero supimos transmitir seguridad y coherencia en el proyecto y así conseguimos acabar el curso sin grandes problemas y con aceptación por parte de la mayoría, maestras, equipo directivo y familias. Este año fue fundamental, de hecho, fue el arranque del maravilloso proyecto que seguimos construyendo. Parece fácil, pero requirió y seguimos haciéndolo, estar explicando continuamente por qué este cambio si los colegios colindantes son más tradicionales, para qué si el alumnado tiene que adaptarse a la dinámica escolar cuanto antes para tener éxito, y donde están las fichas del trabajo que realiza el alumnado. En este curso contamos con maravillosas familias que supieron entender los cambios, observaban a sus hijos/as más implicados en los procesos de aprendizajes a través del juego, de materiales diversos y atractivos y encantadas de las experiencias que sus hijos/as le transmitían y, sobre todo, con la felicidad e ilusión con que lo hacían.

El curso siguiente ya fuimos cuatro las maestras que componíamos el equipo de trabajo, hecho que suponía más compañeras involucradas y reflexionando en el proceso, aportando cambios y visiones que se fueron complementando, pero que 
requería mucho más tiempo y dedicación en el proyecto. El siguiente año éramos ya todo el equipo de infantil involucrado en nuestro proyecto Ambientes de aprendizajes en infantil. Para ello ha sido fundamental la formación y el crear cada curso un grupo de trabajo en colaboración con el CEP de referencia para buscar esos momentos de poner en común vivencias, hablar de niños/as, las dificultades que surgen en los diferentes ambientes, la necesidad de poner materiales como mesa de expresión libre y bibliotecas en cada una de ellas y así, multitud de elementos y factores que intervienen en el día a día de cada aula, pero con la dificultad de aprender a trabajar en equipo y consensuar las tomas de decisiones. Este es otro gran reto para nosotras como maestras.

\section{NUESTRO PROYECTO}

En este proyecto nuestra intención es organizar y proporcionar contextos y situaciones de aprendizaje, experiencias, espacios, materiales y ambientes, que configuren un medio de calidad para el desarrollo infantil, favoreciendo y facilitando los procesos de aprendizaje y socialización.

Todo esto tenía que realizarse de forma coherente ante nuestra normativa de infantil, la cual dice que es una etapa en sí misma, que no es preparatoria para primaria y se trata de poner medios para potenciar el desarrollo de todas las capacidades, ya que como muy bien se expone en la normativa

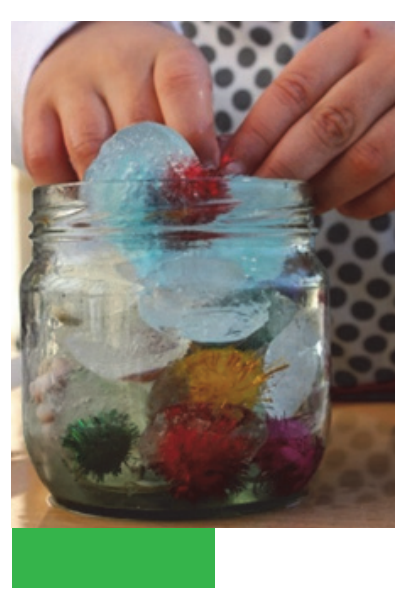

Imagen 2: Manipulación vigente, "la escuela infantil no puede ser concebida como un espacio y un tiempo para la enseñanza transmisora de conocimientos, ni como un lugar para la atención meramente fisiológica y de cuidado, sino como una institución que apoya, favorece y potencia el pleno desarrollo de todas las capacidades" (BOJA, 2008, p. 169).

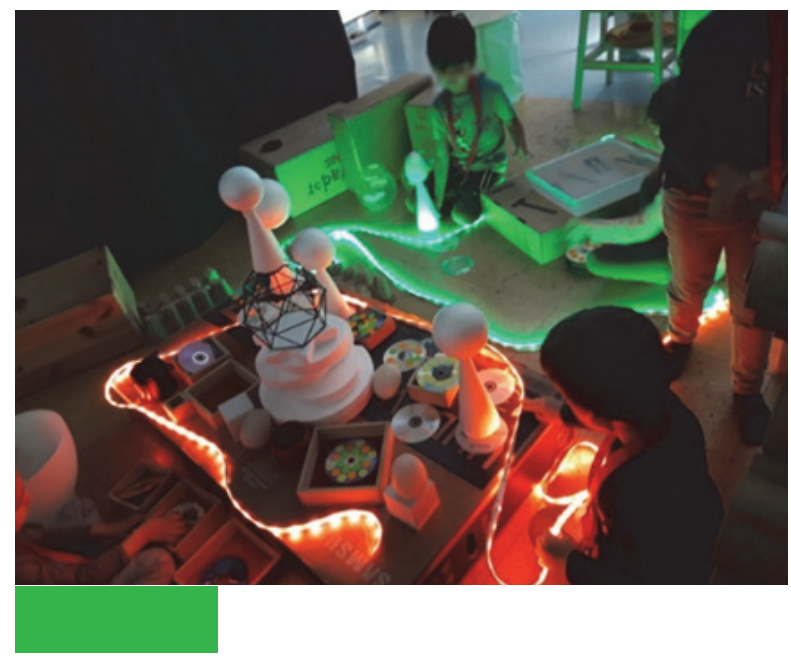

Imagen 3: Creación de escenarios

Por ello sentimos la necesidad de organizar unos ambientes donde se facilite y promuevan diferentes vivencias y recreaciones culturales, valorando la educación como fuente de cultura transformada en conocimientos y saberes que posibiliten y potencien el desarrollo de habilidades, procedimientos para pensar e interpretar el mundo, para expresarse, para convivir y para ser, facilitando el que los niños y niñas de esta etapa conozcan progresivamente la realidad en la que se desenvuelve su vida, $y$ creando un clima afectivo que les ofrezca seguridad y estimule el descubrimiento de sí mismos y de su entorno. Creemos que el conocimiento compartido es indispensable para avanzar en el crecimiento 
personal y comunitario; atender a la diversidad supone reconocer que cada niño/a es una persona única e irrepetible, con su propia historia, afectos, motivaciones, necesidades, intereses, estilo cognitivo, sexo, etc. Esto exige que nuestra escuela ofrezca respuestas adecuadas a cada uno/a.

\section{UNA ESCUELA INCLUSIVA}

Según Calderón (2014) la educación tiene que ver con el acompañamiento a los demás en sus proyectos. Por lo que, como docentes, debemos atender a la diversidad en el aula. Llevando a cabo acciones educativas, programadas y diseñadas por el docente a nivel de aula o centro, para dar respuesta a las necesidades individuales del alumnado, independientemente de las características personales o circunstanciales que presente cada alumno/a, favoreciendo el desarrollo íntegro de la persona, respetando sus intereses, necesidades, ritmos de aprendizaje y ritmos de desarrollo.

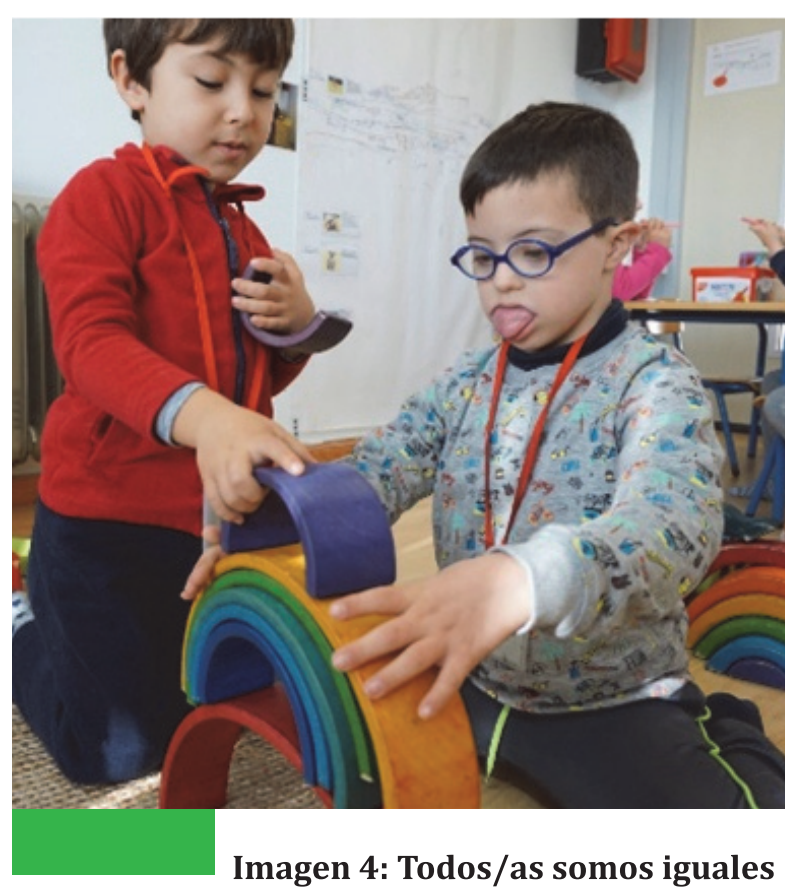

Para ello es necesario que planifiquemos y actuemos de forma abierta, diversa y flexible y con una mirada positiva a las diferencias, siendo los docentes los que nos adaptemos a los intereses de cada niño/a favoreciendo su bienestar y respetando sus ritmos y estilos cognitivos.

La atención a la diversidad se ha de guiar por el principio de favorecer y estimular este bienestar y desarrollo de todos los niños/as, aprovechando las diferencias individuales existentes en las aulas; en este sentido, planteamos actividades y materiales diversos que respondan a diferentes intereses y permitan trabajar dentro de los ambientes, tanto en pequeños grupos como de forma individual, de forma libre o dirigida, pero teniendo en cuenta la curiosidad e interés diferenciado de cada uno/a.

Especial atención y sensibilidad debemos tener con aquellos niños y niñas que presenten necesidades educativas especiales; realizaremos un plan de trabajo y seguimiento del alumnado en colaboración con el equipo de orientación, que nos guiará y fortalecerá en el proceso de ellos/as.

En los casos necesarios, se elabora un "horario de pase por ambientes", en función de sus necesidades e intereses para favorecer una atención más específica y especial, reforzando los aspectos necesarios, favoreciendo su inclusión y, además, al disponer el propio alumnado de su horario de pase de forma visual, le ayuda a anticipar, consiguiendo establecer rutina, seguridad y confianza en sus acciones. 
Es importante destacar la gran colaboración y ayuda del equipo de orientación hacia todo el alumnado de infantil y el apoyo al profesorado en las dificultades del día a día.

Aunque es importante la detección y atención temprana de las necesidades de todo el alumnado, no debemos olvidar en la etapa en que se encuentran, ya que etiquetar no es nuestra labor; nuestro trabajo también se centra en explicar y hacer entender a las familias la importancia de respetar la evolución, desarrollo y maduración de sus hijos/as, evitando realizar comparaciones que solo invitan a la presión y estrés por conseguir antes de tiempo o a la vez, retos, estrategias y

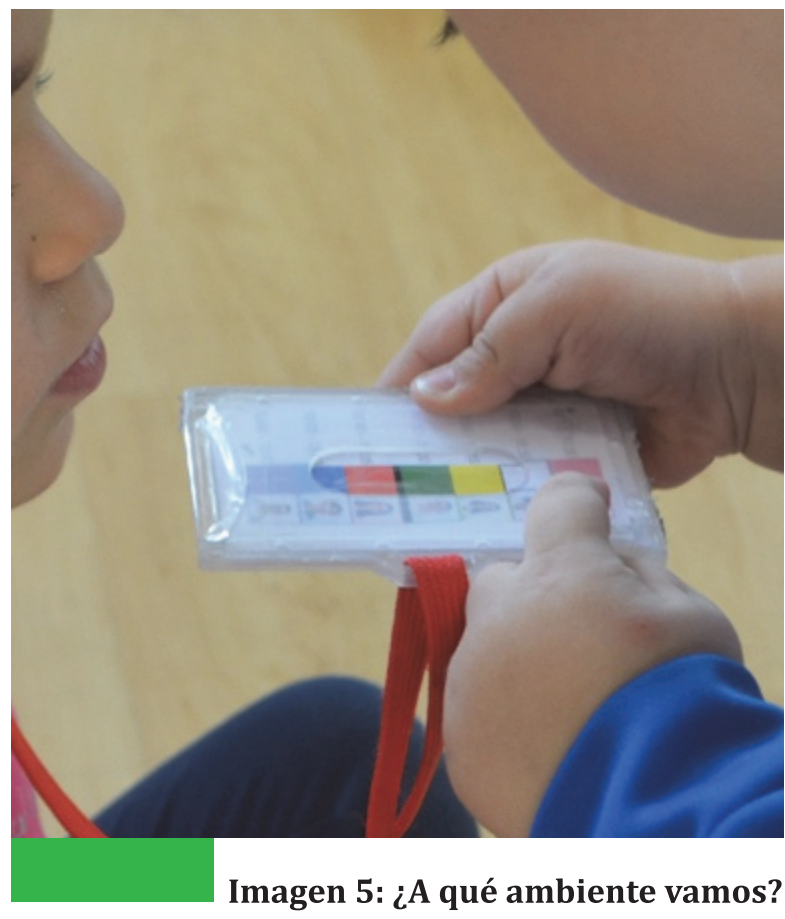
conceptos que necesitan un tiempo y un momento adecuado para cada uno/a.

Nuestra gran labor es disponer, presentar y guiar en los procesos de aprendizaje y acompañarlos en su camino; respetando los ritmos individuales de cada uno/a de nuestro alumnado y entendiendo que:

- No todo el alumnado aprende con la misma facilidad y de la misma manera; al disponer las aulas y espacios exteriores por ambientes, damos oportunidad de acción e interacción con los materiales acordes a sus necesidades y proceso de aprendizaje de cada uno de ellos/as.

- No todo el alumnado está igualmente motivado para aprender; las motivaciones se relacionan estrechamente con los intereses y necesidades personales, de ahí que nuestros planteamientos anteriores hayan cambiado, pasando del trabajo por proyectos, a aprender a aprender según intereses, necesidades y proceso evolutivo de cada uno/a. Nuestra experiencia nos ha llevado a cambiar la metodología del aula y creemos que esta es más respetuosa con las diferencias, sensibilidades, procesos y planteamientos de la normativa vigente de Educación Infantil y de la forma de aprender del ser humano.

- No todo el alumnado aprende de la misma forma y al mismo tiempo; por ello apostamos por unos ambientes libres, donde el alumnado sea el que decida qué hacer, con qué y cuánto tiempo. Un niño/a siempre quiere conocer, curiosear, inventar, tocar, representar y jugar con todo lo que acontece y le rodea. En el siglo XXI las necesidades de formar personas creativas, curiosas, críticas y emocionadas con sus procesos y vida, es fundamental para avanzar en las sociedades actuales y futuras, sin olvidarnos de potenciar sus capacidades y habilidades individuales. 
Lo más importante será sentarnos a hablar de cada uno/a de nuestro alumnado, de sus necesidades, de sus procesos; consensuar entre todos/as un plan de acción y actuación que posibilite el avance y la reflexión de los pasos dados y proponer los siguientes. Se trata de un verdadero trabajo en equipo, de la implicación de todo el equipo docente de infantil y de orientación, para atender a la diversidad de todo nuestro alumnado.

\section{NUESTRO ROL COMO MAESTRAS/OS}

Uno de los grandes pilares en el que se apoya este proyecto es el ser coherente entre lo que pensamos y hacemos, repensando continuamente e intentando darle sentido a nuestra acción como maestras/os que cambia por completo, ya que rompemos con la tradicional creencia que somos las que transmitimos los conocimientos al alumnado. Nosotras/os apostamos y creemos que el aprendizaje en estas edades emana de dentro hacia fuera, de la interacción y acción del alumnado con los materiales y experiencias que realizan, que favorezca el movimiento y las relaciones entre ellos, ya que en nuestros momentos de ambientes todo el alumnado de infantil se mueve interactuando con compañeros/as de diferentes edades, favoreciendo el aprendizaje por imitación, la ayuda y la colaboración.

Por ello nuestro papel como maestras/os cambia, ya que ahora tratamos de acompañar al alumnado desde el respeto, intervenir para facilitar, hablar en tono adecuado, eliminar el lenguaje infantil, organizar con estética los espacios, aportar materiales más naturales y menos estructurados, y asumir un papel de provocadora de situaciones, retos y actividades atractivas llenas de contenido e ilusión.

Para nosotras/os el romper con rutinas y formas de actuar asentadas como buenas en la práctica, nos empuja a diseñar y consensuar estrategias que nos acerquen a la escuela que soñamos; ahora acompañamos y guiamos al alumnado con otra mirada, con paciencia, dando tiempo a los procesos y estando en continua observación y acción para provocarles, presentándoles retos y acciones más acordes a sus realidades personales, reflexionando sobre estas y afrontando en equipo aquellas dificultades que intentamos solucionar, enriqueciéndonos a todas.

Otro aspecto muy importante y que cambia de forma radical es que ya no somos maestras/os de 25 alumnos/as, sino que todo el alumnado de infantil entra en los ambientes, provocando entre todos co-

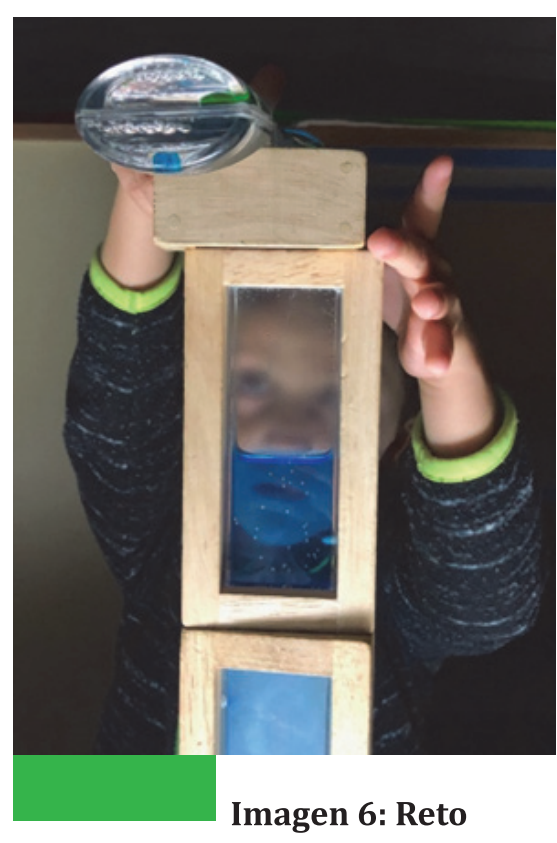
municaciones y relaciones más variadas y abiertas, donde el alumnado cuenta con más opciones para elegir a otros/as en sus relaciones y tener otros adultos como referentes. 


\section{LOS AMBIENTES DE APRENDIZAJE}

Nuestro centro es de línea tres, por lo que contamos con tres unidades en cada nivel. Hemos diseñado nueve ambientes diferentes que pertenecen a cada clase, diferenciadas por colores, donde el alumnado porta consigo una medalla del color de su ambiente para facilitar la recogida de observaciones que sustentarán parte de la evaluación. El décimo ambiente es el exterior, del que se encarga la maestra de apoyo.

Las aulas de nuestra escuela de infantil sufren cada curso una transformación alimentada por la aportación y vivencias de cada una de las maestras/os que pasan por ellas; son espacios vivos, cambiantes, que se enriquecen con las ideas de todas/os, con las experiencias del alumnado y con el aporte de materiales elegidos y seleccionados por nosotras/os.

Los ambientes que hemos diseñado y creado en nuestra escuela están pensados para desarrollar todas las capacidades y posibilidades expresivas del alumnado, apostando por el juego como el mejor recurso para motivar y crear aprendizajes.

"El verbo jugar solo se puede conjugar con el verbo dejar" (Tonucci, s. f.).
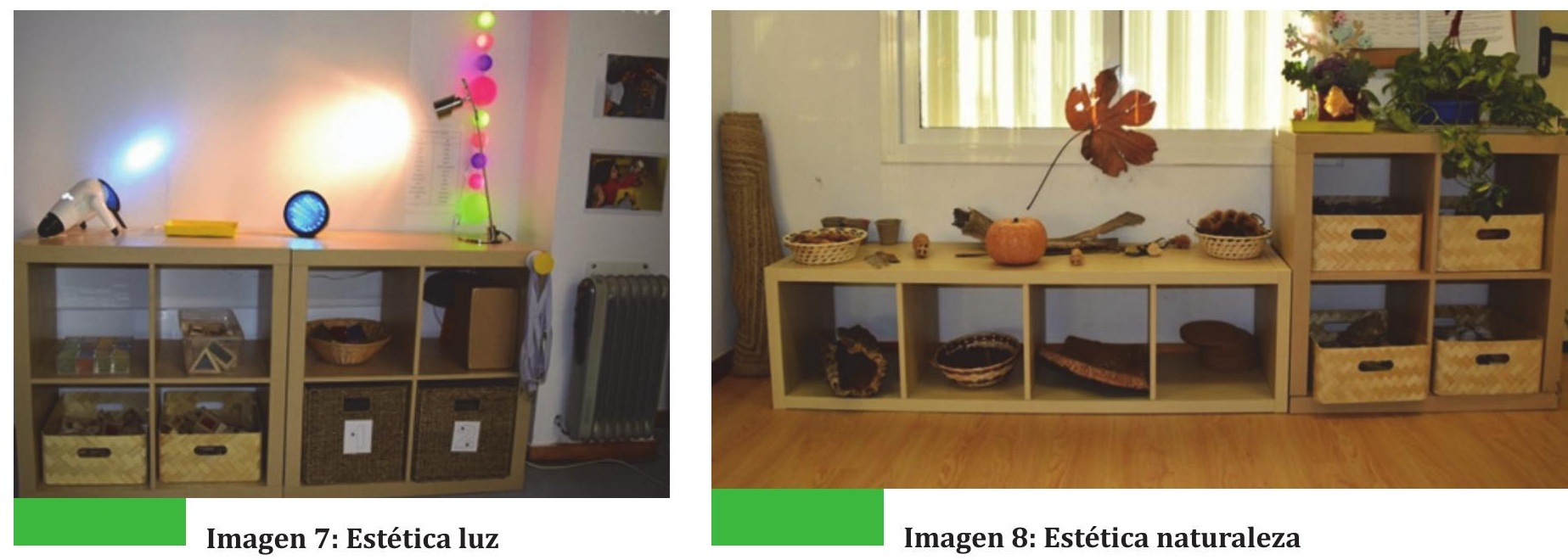

Nos encontramos los siguientes ambientes de aprendizaje:

\subsection{Ambiente de psicomotricidad $y$ vida práctica}

El desarrollo de la psicomotricidad permite a los niños/as explorar, investigar y conocer su cuerpo, así como el mundo que les rodea, superando dificultades y enfrentándose a sus limitaciones, superando sus miedos y disfrutando de conocer a los otros, desarrollando la fantasía, la iniciativa propia y la expresión libre.

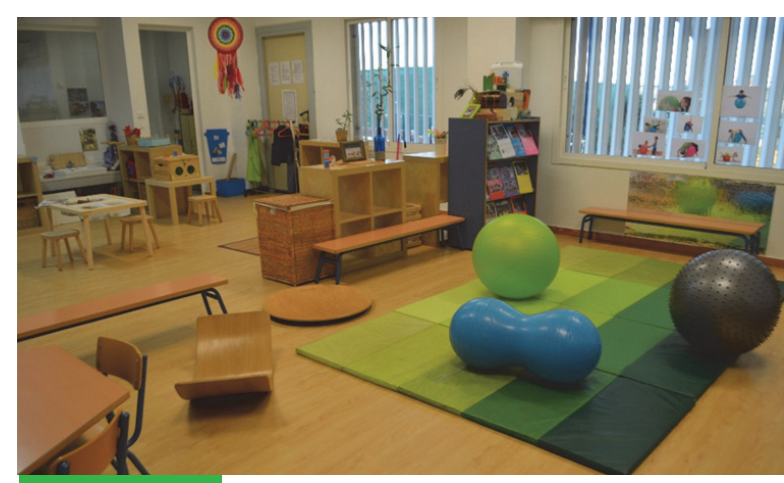

Imagen 9: Ambiente psicomotricidad y vida práctica 
Con este ambiente pretendemos que el alumnado vaya adquiriendo autonomía en la realización de las actividades de vida práctica, progresando en la coordinación y control del cuerpo en situaciones psicomotrices, descubriendo sus posibilidades de acción y de expresión, explorando nociones básicas de orientación en el espacio del ambiente, favoreciendo el dominio del movimiento corporal para avanzar en la relación y la comunicación con los demás y los objetos estimulando la capacidad sensitiva.

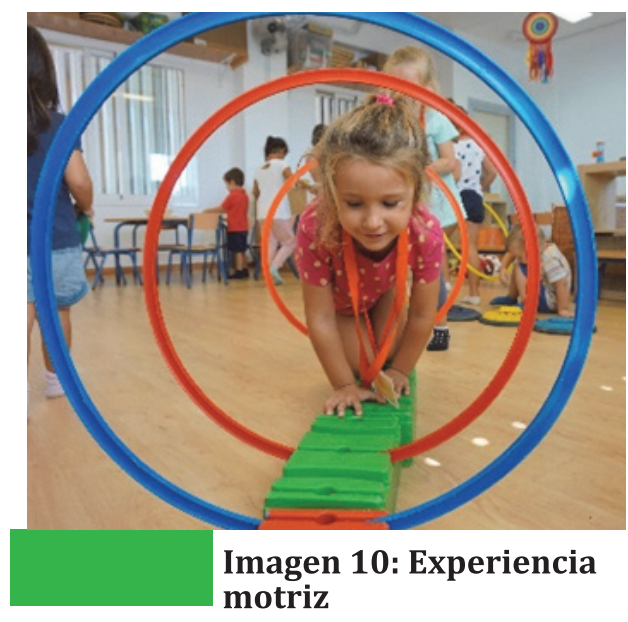

\subsection{Ambiente de construcción}

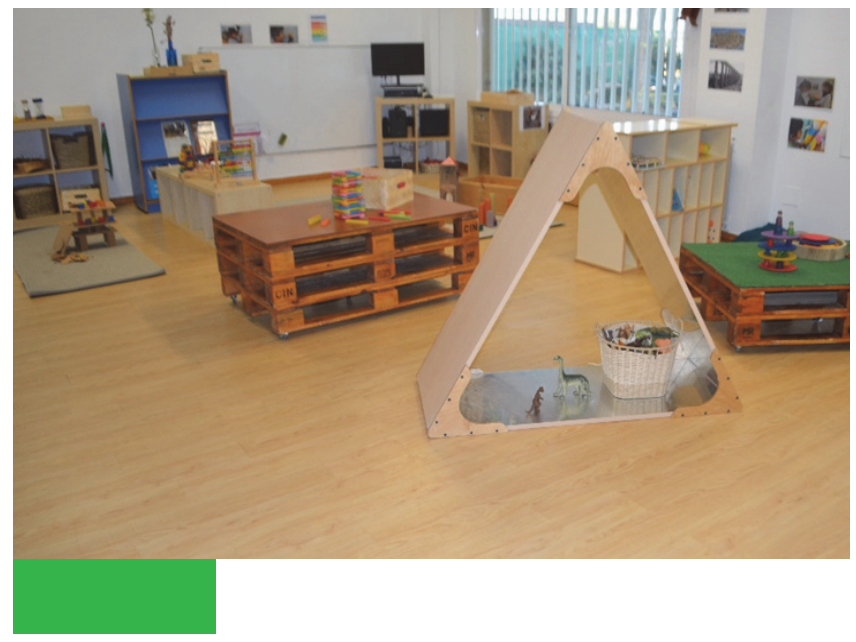

Imagen 11: Ambiente de construcción

Los materiales y juegos de construcción además de ser una de las actividades preferidas del alumnado, potencian y desarrollan sus capacidades en todos sus ámbitos. Con este ambiente pretendemos que el alumnado desarrolle su creatividad, la coordinación óculo-manual, la lógica y la visión espacial, experimentando con reglas físicas, descubriendo cualidades de los materiales, ejercitando la concentración e imaginación, el trabajo cooperativo, la expresión oral, el respeto al juego, así como las construcciones de los demás e intentando reforzar su autoestima.

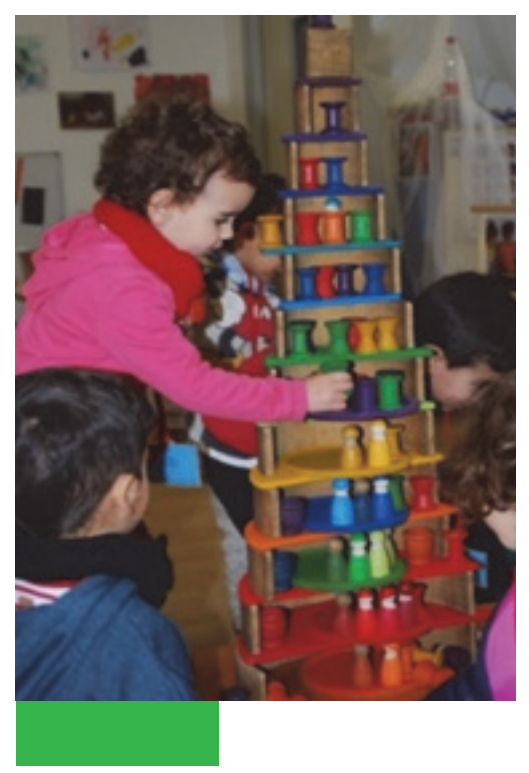

Imagen 12: Torre

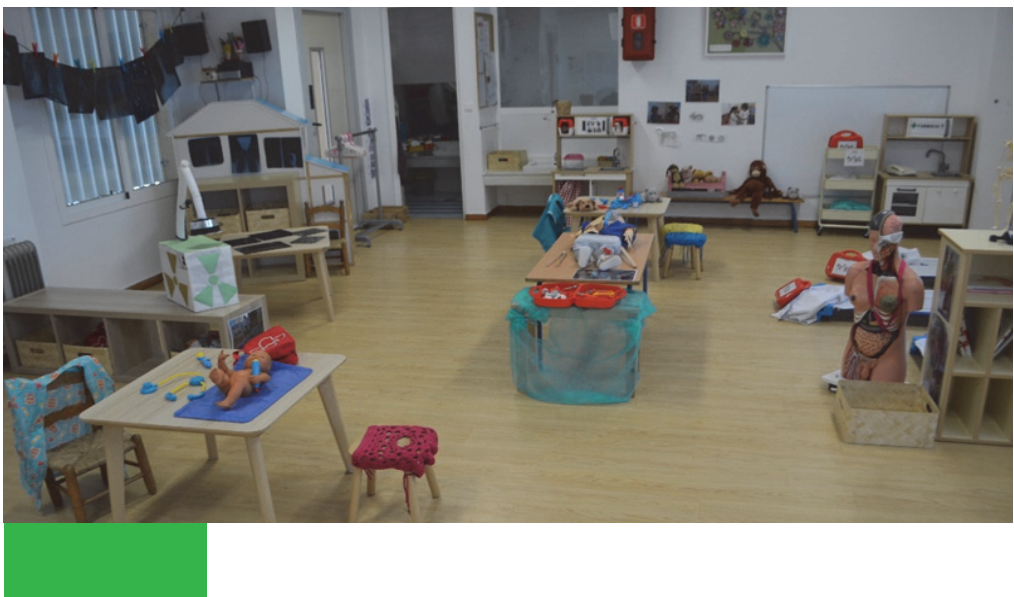

Imagen 13: Ambiente de juego simbólico 


\subsection{Ambiente de juego simbólico}

El juego simbólico es un tipo de juego en el que el alumnado puede desempeñar diferentes roles, imitando situaciones que observan en la vida cotidiana de los adultos; para hacerlo utilizan la imaginación y crean representaciones mentales. Este tipo de juego es una vía para: proyectar sus miedos, tensiones y conflictos internos, enriquecer su conocimiento social, entender los roles que ejercen las personas de su entorno, favorecer el desarrollo emocional, cognitivo y sus habilidades sociales, aprender a respetar normas y fomentar su autonomía y creatividad. Con este ambiente pretendemos

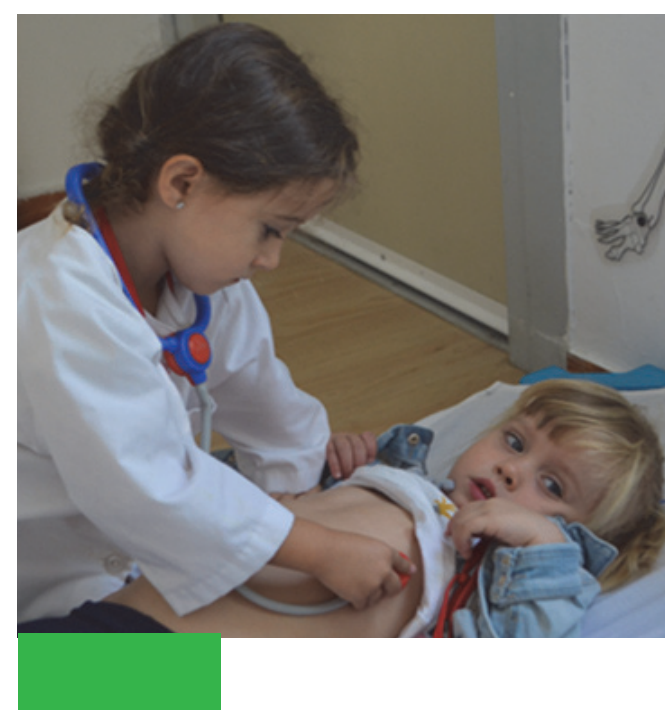

Imagen 14: Ambiente de juego simbólico favorecer el juego compartido, desarrollándose el alumnado emocionalmente, elaborando sus propias vivencias, asimilando y comprendiendo el entorno que le rodea, desarrollando su capacidad de imaginar, promoviendo la interacción lingüística y la socialización.

\subsection{Ambiente creativo}

La creatividad es un elemento muy importante que ayuda a desarrollar y expresar el potencial humano, tanto a nivel cognoscitivo e intelectual como conductual y afectivo. En este ambiente intentamos desarrollarla $\mathrm{y}$ estimularla invitándoles a favorecer el pensamiento libre

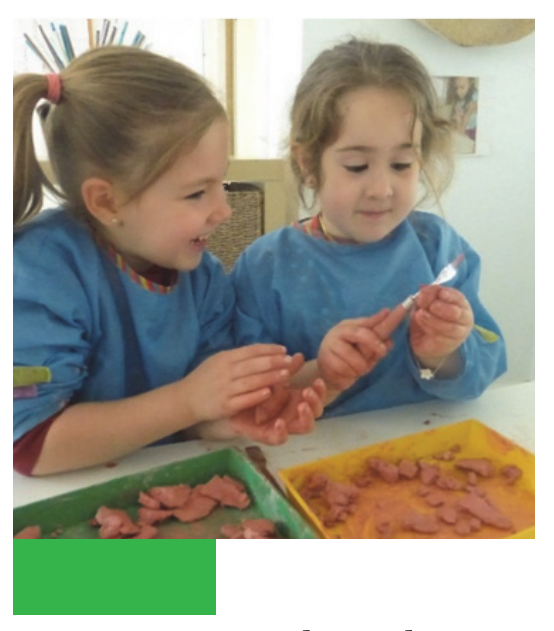

Imagen 16: Creando con barro

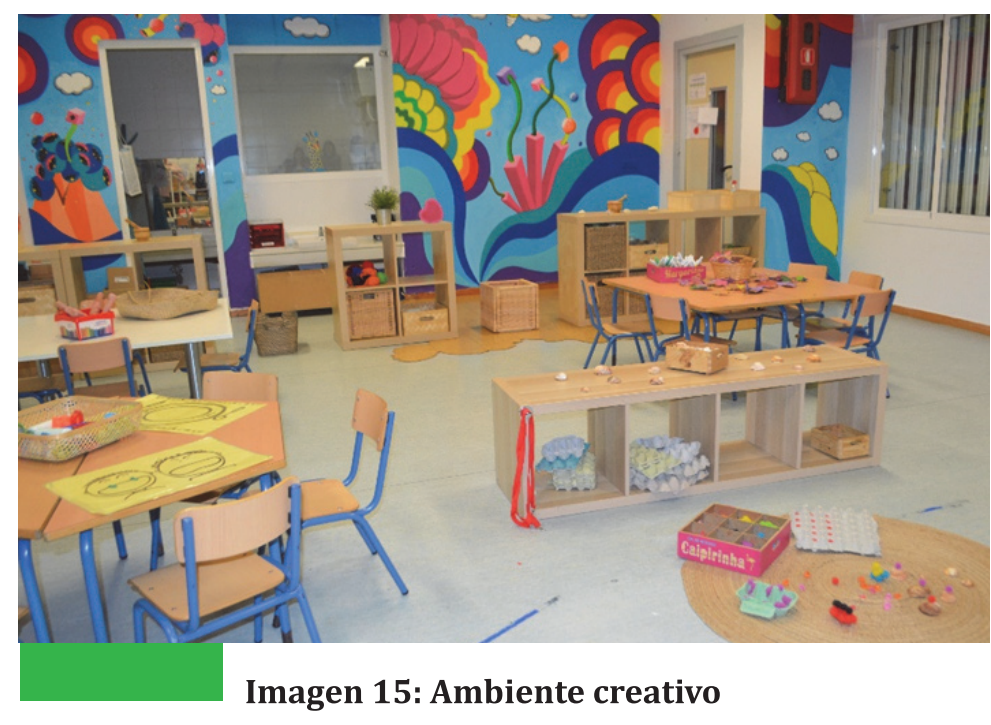

y divergente, dando rienda suelta a la imaginación y a las artes plásticas. Con este ambiente pretendemos que el alumnado vaya aprendiendo a anticipar proyectos y organizar su elaboración, a explorar a través de los sentidos con distintos materiales, valorando positivamente y respetando las elaboraciones propias y ajenas, reforzando habilidades básicas relacionadas con la psicomotricidad fina, la orientación espacial, la permanencia del objeto y la lateralidad, fomentando la imaginación y promoviendo el intercambio comu- 
nicativo y las habilidades socioemocionales, así como la cooperación y cuidando del entorno a través de las posibilidades de los materiales del reciclado.

\subsection{Ambiente de arte}

La pintura y el dibujo ofrecen al alumnado la posibilidad de expresar y comunicar sus ideas, experiencias, sentimientos, imaginación, ayudándoles a canalizar emociones y pensamientos que saldrán de su mundo interior, pudiendo ser compartidos con otros o simplemente explorando acciones que les provoquen disfrute y pla-

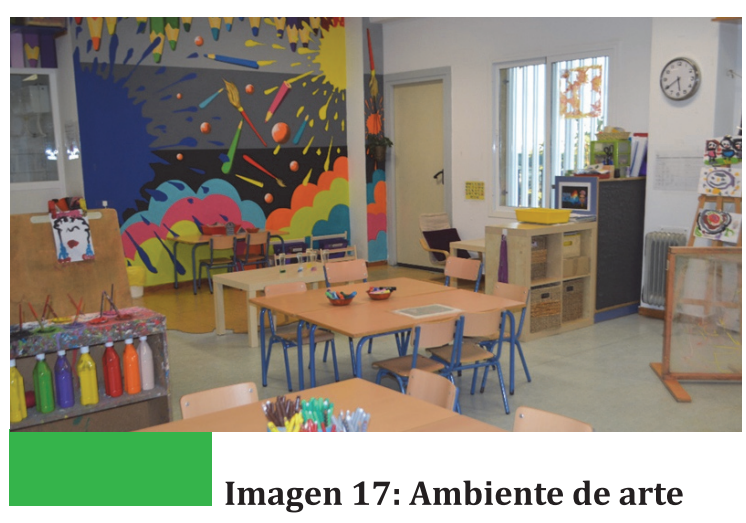
cer en su realización. Con este ambiente

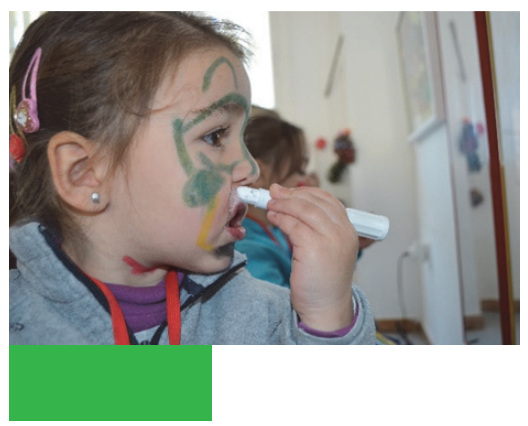

Imagen 18: Me convierto en...

pretendemos que el alumnado experimente y se exprese a través de la pintura y otros materiales artísticos, conociendo diferentes técnicas, creando sus propias composiciones con diversos materiales observando el resultado, fomentando el respeto y el conocimiento de obras artísticas propias y ajenas, así como la comunicación e intercambio de acciones y pensamiento entre el alumnado a través del arte.

\subsection{Ambiente de lectoescritura}

A través del lenguaje los niños y niñas son capaces de estructurar su pensamiento, conocer el mundo que les rodea y establecer relaciones con los demás. En este ambiente los niños van construyendo sucesivamente el conocimiento sobre las palabras, las letras y otras habilidades relacionadas con el desarrollo lingüístico, siempre vinculado al significado y al uso

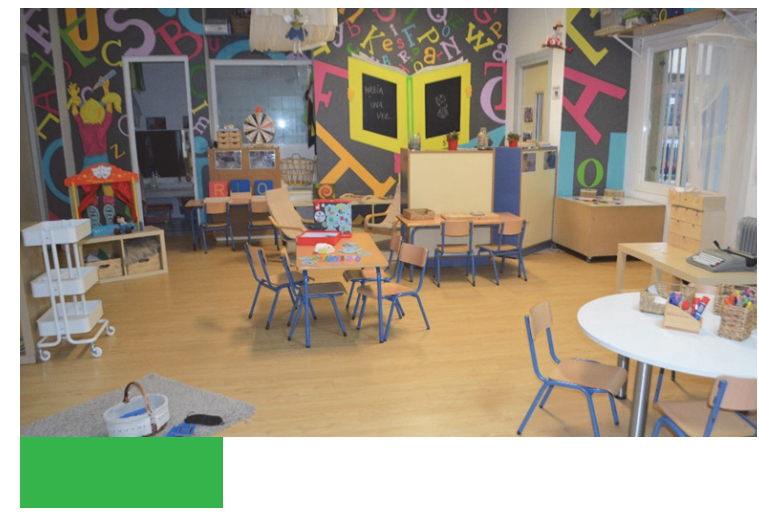

Imagen 19: Ambiente de lectoescritura

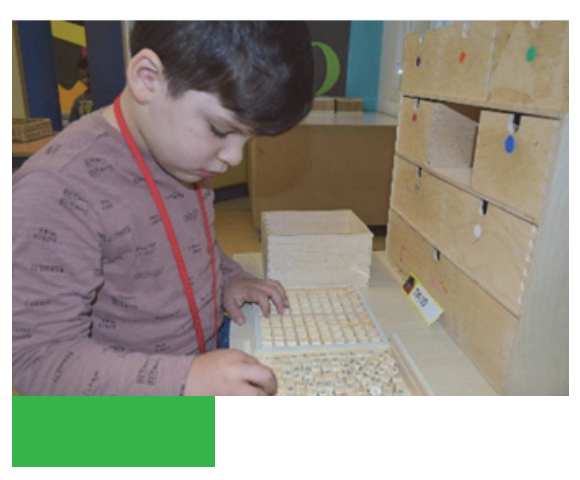

Imagen 20: Componiendo nombres

que estos hacen en distintas situaciones comunicativas. En este ambiente pretendemos que el alumnado vaya desarrollando habilidades comunicativas, indagando sobre el uso social del lenguaje y las diferentes formas de expresión, activando la invención de relatos y cuentos, así como la manipulación y relación con diferentes tipos de texto. 


\subsection{Ambiente de lógica-matemática}

El pensamiento lógico-matemático es fundamental para comprender conceptos abstractos, razonamiento $\mathrm{y}$ comprensión de relaciones. Es a través de las relaciones del alumnado con los materiales, juegos y experiencias, como se potencia las habilidades que contribuirán al desarrollo de la inteligencia matemática, así como a la capacidad de entender conceptos y establecer relaciones basadas en la lógica. Con

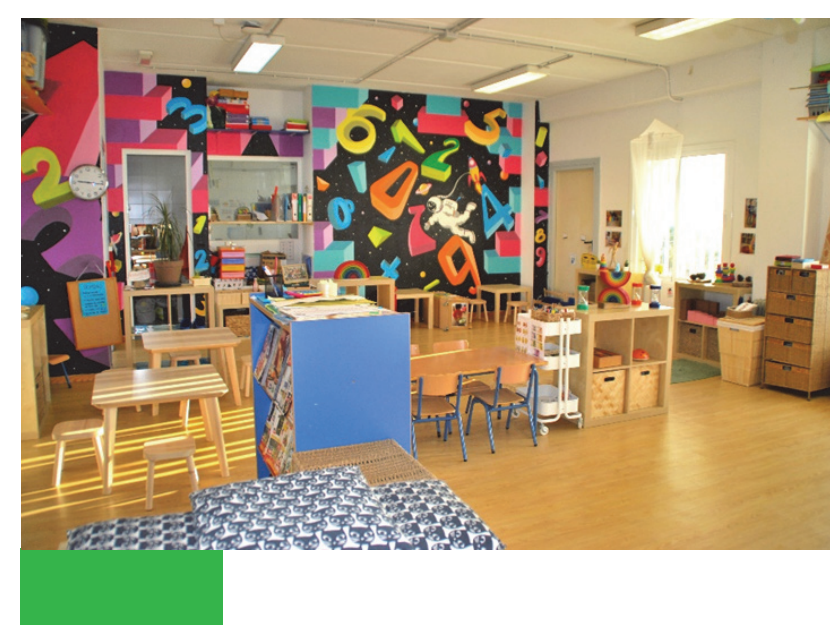

Imagen 21: Ambiente de lógica-matemática este ambiente pretendemos que el alumnado vaya conociendo las cualidades y relaciones de los objetos mediante la observación y manipulación sobre ellos, incitándolos al uso de un pensamiento lógico-matemático en situaciones cotidianas, desarrollando la autonomía y la creatividad en la resolución de problemas, así como un espíritu crítico, aprendiendo a cooperar y a usar habilidades sociales respetando las normas de los juegos.

\subsection{Ambiente de naturaleza y experimentación}

La observación, manipulación y acción que realiza el alumnado sobre los materiales crea infinidad de conocimientos y experiencias que enriquecen la vida de estos, las

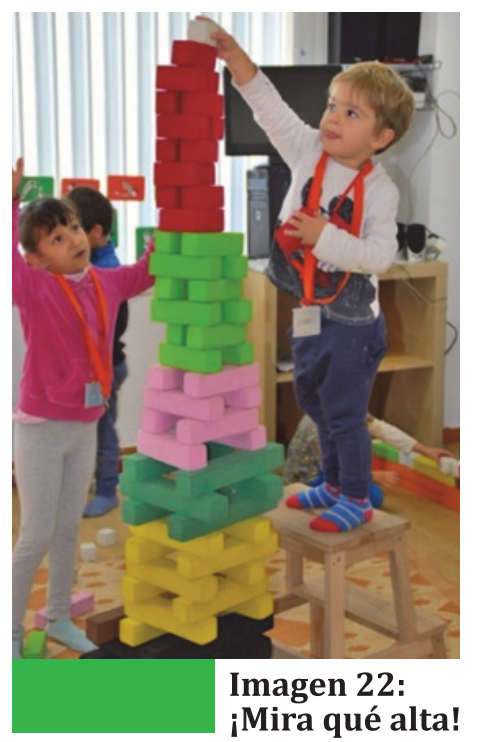
relaciones con los otros y las vivencias con otros seres que habitan en dicho espacio. Con este ambiente pretendemos que el alumnado vaya descubriendo las propiedades de los objetos, realizando experiencias que le inviten al conocimiento de sus acciones y el descubrimiento de sus resultados, fomentando las relaciones con otros seres vivos, así como su cuidado, conocimiento y respeto.

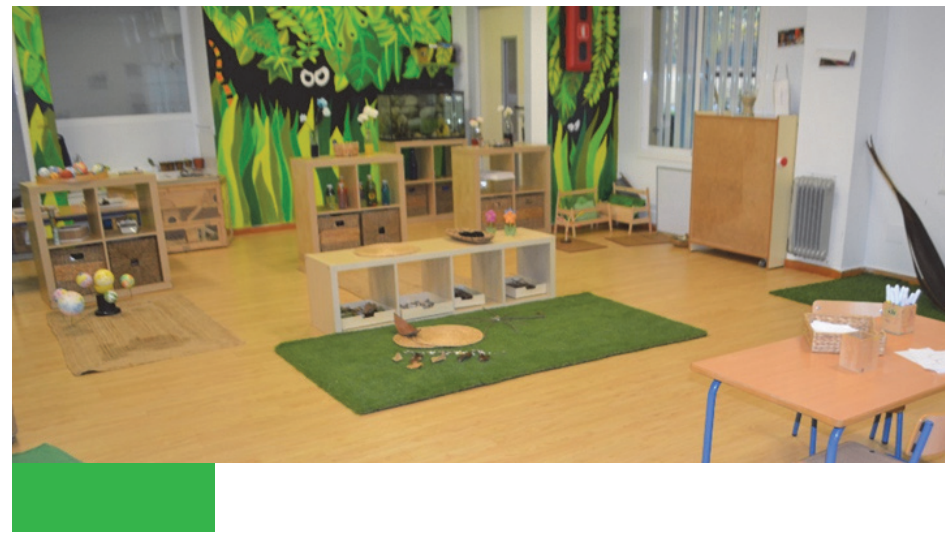

Imagen 23: Ambiente de naturaleza y experimentación

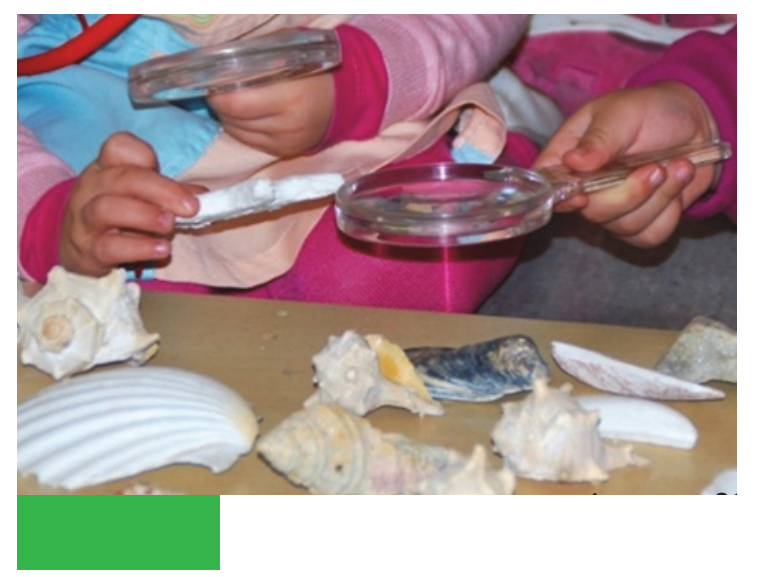

Imagen 24: Observación 


\subsection{Ambiente de luz}

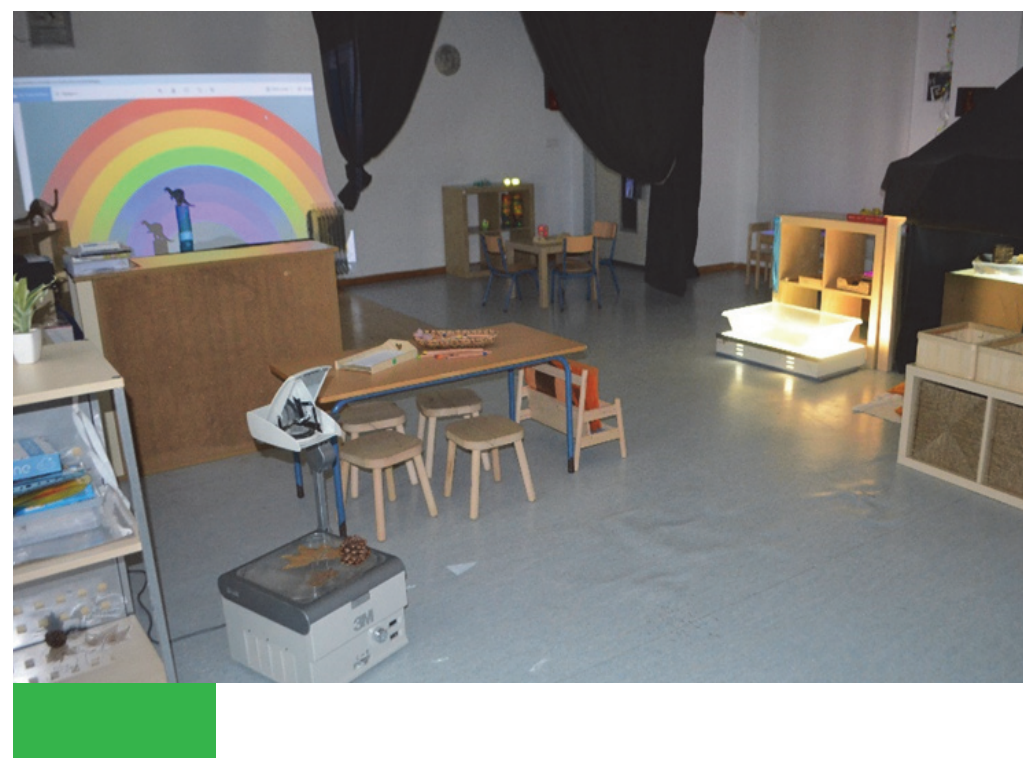

Imagen 25: Ambiente de luz

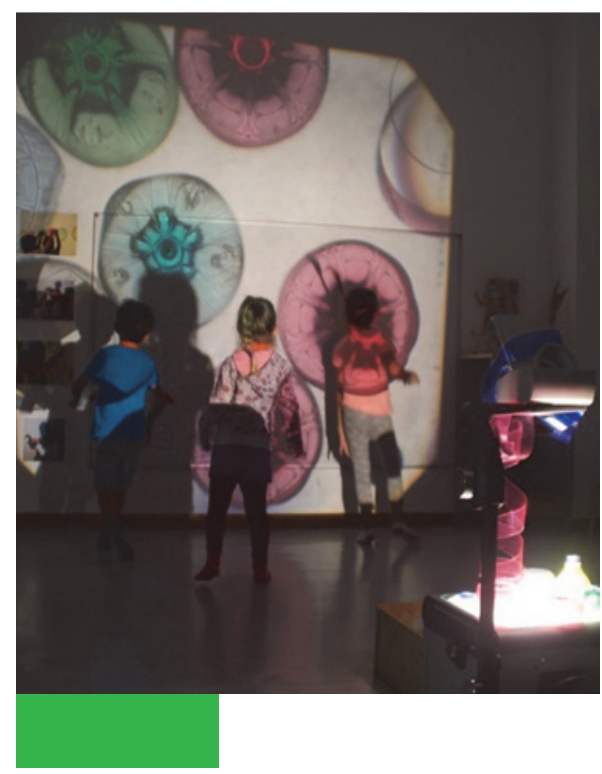

Imagen 26: Jugando con el retroproyector

El niño conoce el mundo que le rodea a través de los sentidos; uno de estos es el de la vista, al que le acompaña el deseo de tocar, manipular y experimentar. El alumnado siempre está dispuesto a encontrar multitud de posibilidades lúdicas, y este espacio sin luz y multisensorial, le abre un mundo infinito de posibilidades donde interactúan con los diferentes materiales, luces, sombras y su propio cuerpo. Con este ambiente pretendemos que el alumnado fomente la curiosidad y estimule su creatividad, descubriendo y experimentando con diferentes fuentes de luz, percibiendo y diferenciando las diferentes texturas, formas, y experimentando con las sombras que proyectan los objetos y el cuerpo, manipulando materiales para descubrir los efectos de la luz, la ausencia de esta y sus propiedades, así como la ayuda a superar el miedo a la oscuridad y las sombras, favoreciendo el desarrollo de la percepción óculo manual.

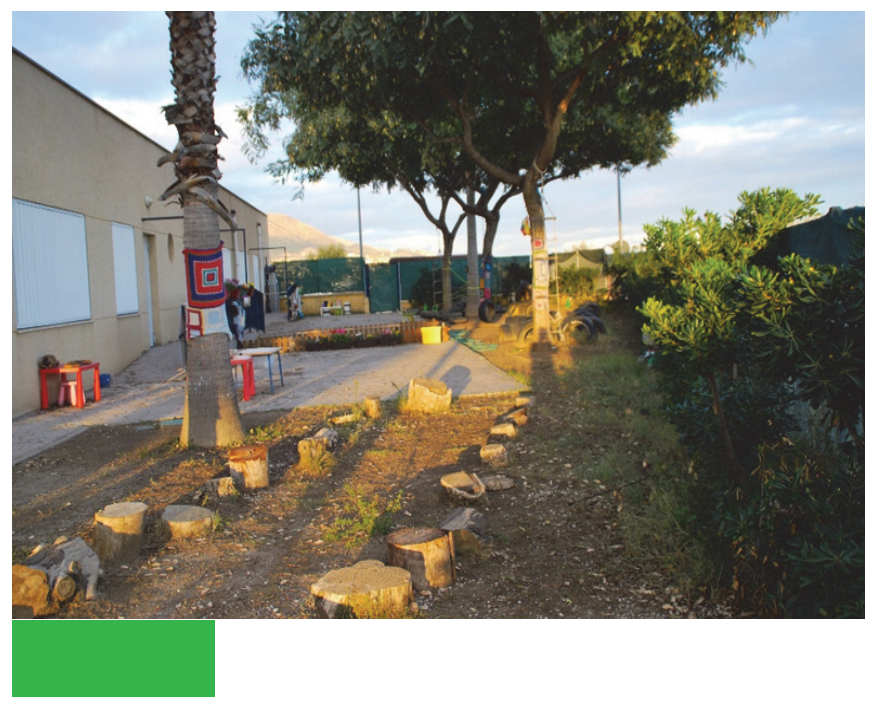

Imagen 27: Ambiente exterior

\subsection{Ambiente exterior}

El contacto directo que el alumnado tiene con el entorno a través de sus sentidos, el movimiento y el equilibrio favorece la óptima maduración biológica despertando las ganas de aprender y de explorar, facilitando el desarrollo motriz y activando su imaginación a través del juego. Con este ambiente pretendemos que el alumnado experimente las propiedades del sonido a través de instrumentos y 


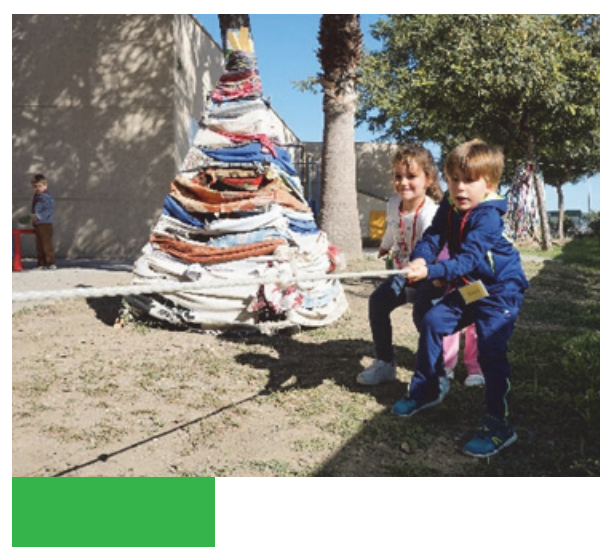

Imagen 28: Probando nuestra fuerza

objetos de la vida cotidiana, desarrollando habilidades motoras, de coordinación y equilibrio a través de las experiencias y materiales que les proponemos, explorando el entorno inmediato a través de los sentidos, respetando y cuidando el entorno vegetal y animal.

\section{NUESTRA JORNADA}

Durante la jornada escolar el alumnado comienza saludando con su familia a la maestra/o en la puerta de su clase y tras una sesión de asamblea con juegos y actividades, pasamos al momento de ambientes, donde cada alumno/a elige a dónde acudir entre los diez espacios diferentes. En estos momentos todo el alumnado de infantil puede acceder li-

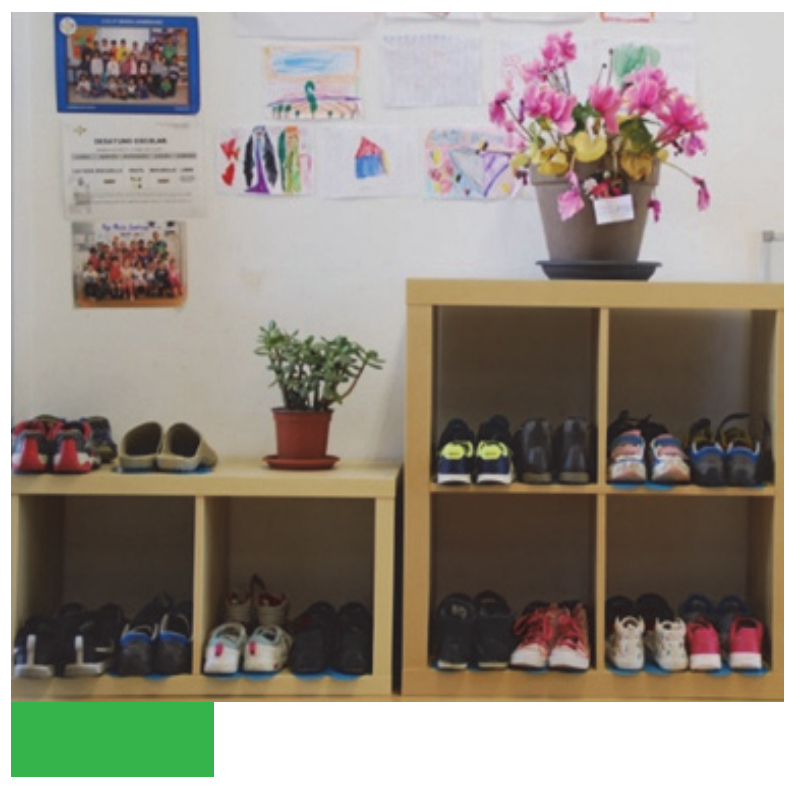

Imagen 29: ¡Qué bien se está descalzo! bremente a ir al ambiente que desee, pudiendo encontrarlos en estos mezclados de las tres edades y de diferentes aulas.

El acceso a cada ambiente está delimitado por unas huellas (muebles que hacen de zapatero) que encuentran en la entrada de cada aula, ya que todo el alumnado y las maestras/os se descalzan, regulando de esta forma el aforo al interior. Durante una hora y cuarto el alumnado tiene la posibilidad de acceder a los ambientes que elija y realizar en ellos las actividades y juegos que deseen; como toda buena organización, esta requiere de unas normas y formas de hacer, ya que los ambientes están dotados de diversos materiales y mobiliarios que conviven en armonía e invitan al alumnado a tocar, hacer, emocionarse; y nosotras/os nos encargamos de observa, ayudar y acompañarlos en sus experiencias y vivencias.

Después llega el momento del aseo y la alimentación para reponer energías y un ratito de juego de patio. Al terminar este, todo el colegio realiza un mantra y volvemos a nuestras aulas de referencia, donde tenemos una pequeña sesión para la relajación, cuento y actividades diversas.

Al terminar, comienza el segundo momento de ambientes, donde el alumnado podrá elegir otros espacios, o terminar algo que no pudo, o presentar a sus amigos/ as algún material que ha descubierto; en definitiva, vuelven a elegir solos o en compañía de algunos allegados, dónde ir. 
Y antes de finalizar la jornada volvemos a tener una asamblea en las aulas de referencia, para hablar sobre lo que hemos hecho, descubierto y observado, lo cual alentará a otros/as a curiosear y poder encontrar mañana ese espacio tan tentador.

En definitiva, nuestra jornada escolar se sustenta en tres momentos diferentes de asambleas, donde cada nivel, programa contenidos y actividades a desarrollar, y dos momentos de ambientes, cuyos espacios a comienzos de curso han sido diseñado con la ayuda de todas/os y cada maestra/o le va dotando de vida durante el curso escolar, cambiando espacios, materiales y propuestas que nos ayuden a la consecución de nuestros objetivos.

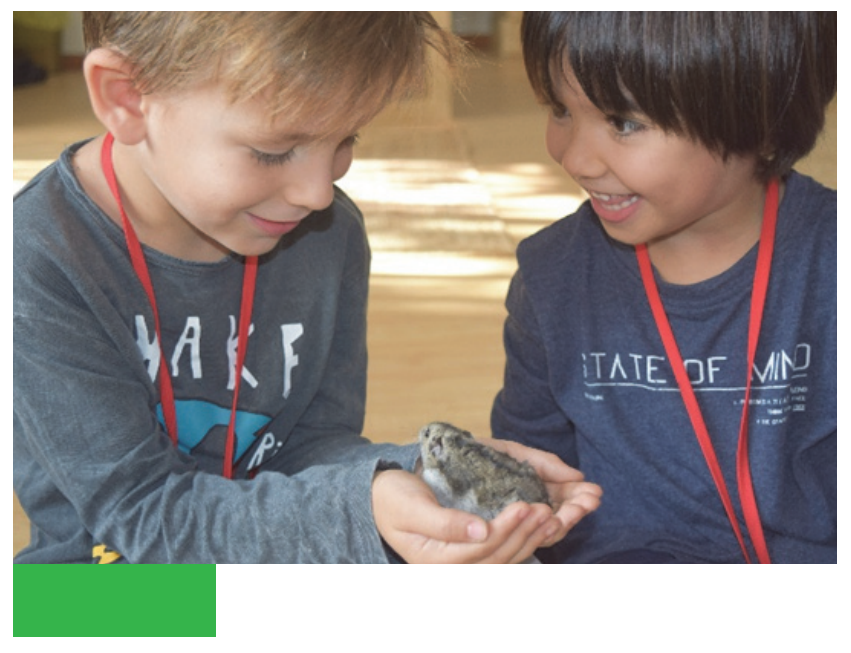

Imagen 30: Miradas cómplices

Como hemos comentado anteriormente, sentíamos la necesidad de formarnos a través de un grupo de trabajo, compartiendo nuestras inquietudes, donde demos forma a nuestro proyecto y donde poco a poco vayamos concretando aspectos tan importantes para nosotros como: concepto de infancia, rol del maestro/a, maneras de compartir la información que tenemos, documentaciones, qué tipo de fotografía buscamos, evaluación, metacognición... El curso pasado, decidimos elaborar un "botiquín de asambleas"

con actividades de diferentes ámbitos, como lectoescritura, lógico-matemática, relajación- meditación- yoga, música- bailes- ritmos..., secuenciándolas y temporalizándolas para los diferentes niveles, 3 , 4 y 5 años y por trimestres.

En la primera asamblea de acogida_cada tutora/or con su grupo de referencia trabaja partiendo de actividades relacionadas con la lógica-matemática y la lectoescritura, basándonos principalmente para el trabajo de conceptos matemáticos en José Antonio Fernández Bravo y su forma de entender las matemáticas, siempre desde la manipulación y las actividades significativas para ellos y ellas. Además del trabajo con regletas, semanalmente, cada tutoría dispone de dos sesiones de media hora para el aprendizaje de las matemáticas a través de estas; el grupo clase se reduce a dos grupos para estas sesiones. Durante esta sesión de media hora el ambiente permanece cerrado y el otro grupo de alumnado disfruta del resto de ambientes. Con ellas se pretende que el alumnado pueda manipular y disfrutar con este material, desarrollar y construir su pensamiento-lógico matemático.

En cuanto a la lecto-escritura, la tratamos desde una perspectiva constructivista partiendo de algo tan significativo como su nombre y respetando los niveles de conocimiento que señala Teberosky y Tolchinsky (1989): 
- Escritura presilábicas.

- Escritura silábica. (Ejemplo para pelota; EOP, EOA, PLT.)

- Silabicoalfabéticas (pelta)

- Alfabéticas (pelota)

En las asambleas realizamos actividades partiendo de los diferentes tipos de texto, comenzando en primer lugar desde 3 años con el trabajo del nombre propio; para ello nos ayudamos de las medallas que cada alumno/a lleva consigo, donde aparece escrito su nombre en mayúscula, realizando diversos juegos para ver cuál es la letra inicial, quién tiene el nombre más largo o más corto, quién tiene determinada letra, además de diversos juegos de conciencia fonológica. ¿Cómo suenan mis letras?, rimas diversas, poesías, canciones... donde los niños y niñas tienen la oportunidad de aproximarse a la lecto-escritura de manera funcional y significativa.

La segunda asamblea de relajación la dedicamos a trabajar desde el mindfulness y diversas técnicas de relajación o el yoga para niños y niñas.

El mindfulness y la disciplina positiva forma parte fundamental del día a día en los ambientes, trabajamos desde la educación emocional y el mindfulness más concretamente, fusionando mente y corazón, desarrollando también nuestro lado espiritual y os preguntaréis ¿Por qué desde tan pequeñitos?

Porque estamos convencidas/os que hay que empezar desde edades tempranas a trabajar desde el amor, la confianza, el respeto y sobre todo la fantasía y la magia, esa gran olvidada para los mayores. Pues tal y como Mora (2013) subtitula su libro: "Solo se puede aprender aquello que se ama".

\section{¿Qué es el mindfulness?}

El mindfulness es la plena conciencia, la atención centradas en este preciso momento, deliberadamente y sin juzgar la experiencia.

El Mindfulness para niños nos brinda toda una serie de posibilidades para mejorar desde bien temprano su atención, para ejercitar su cerebro en la empa-

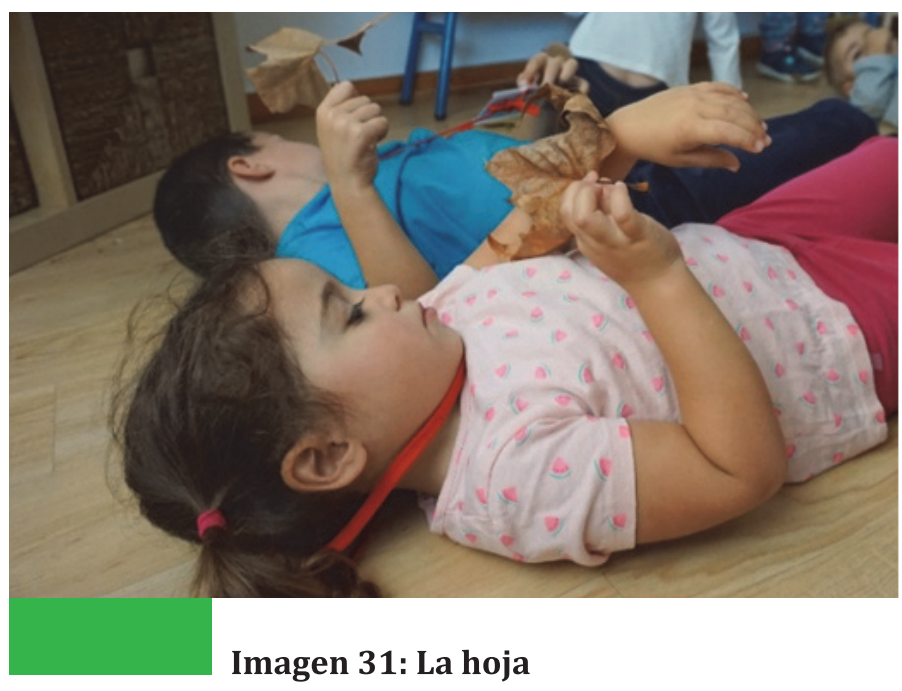
tía, en la calma y la gestión emocional. Asimismo, iniciar a nuestros pequeños/as en el mundo de la meditación facilita que puedan conectarse mucho mejor consigo mismos. Ofreciéndoles a nuestros niños/as un espacio seguro, libre de estrés, libre de angustia. 
Enseñémosles dónde está su centro gracias al Mindfulness, acercándolos a un espacio de calma donde entender mucho mejor sus emociones.

¿Cómo lo trabajamos o desarrollamos en nuestras asambleas de relajación?

Siempre comenzamos con "pranayamas", es decir diferentes tipos de respiraciones: Respiración abdominal o diafragmática, Kapalabhati o tren de Kapalabhati, Bhramari o respiración de la abeja, cantamos diferentes mantras, realizamos juegos de atención plena cómo atrapar el silencio, un determinado sonido que emite una campanita, unos crótalos, canciones de yoga, diferentes "asanas" posturas o cuentos motores en los que viajamos por el bosque, el mar o cualquier otro lugar imaginario y mientras relatamos el cuento, vamos realizando diferentes posturas de yoga siempre imitando a animales o elementos de la naturaleza,

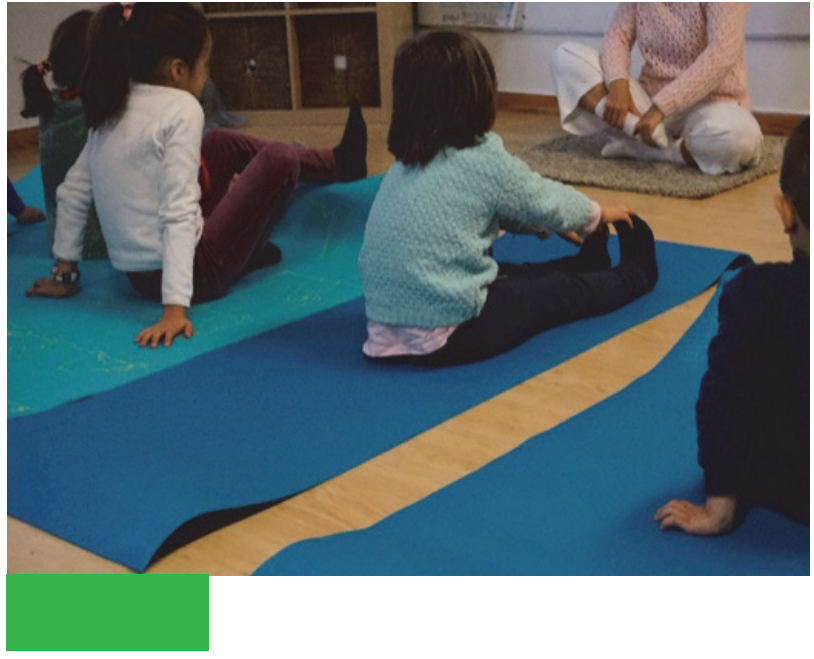

Imagen 32: Atención plena

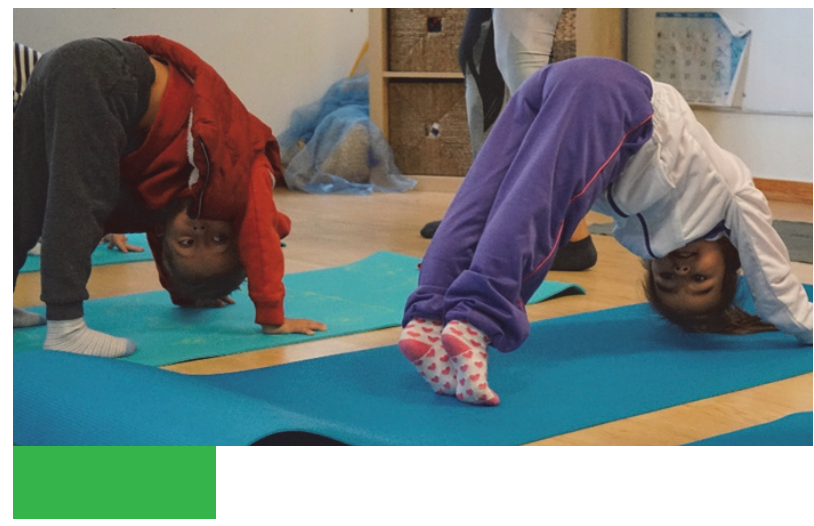

Imagen 33: Posturas de yoga la montaña, el perro, el gato, la cobra...

Partiendo de esta forma de hacer escuela también creemos y nos basamos en la Disciplina Positiva.

La disciplina positiva lo que quiere es guiar a los niños a adquirir habilidades sociales que le resulten útiles para su vida. Para ello utiliza habilidades sociales como la asertividad, la empatía y la escucha activa. Los valores principales que defiende la disciplina positiva son: Las relaciones horizontales, igualdad para todos los seres humanos, la educación orientada a la autorregulación, la responsabilidad personal, la motivación intrínseca, la creación de opinión propia, la capacidad de tomar decisiones, la adquisición de habilidades sociales y el fomento de la inteligencia emocional, y la visión de los errores como oportunidades de aprendizaje. (Ortega, 2016)

A menudo no dedicamos tiempo en esta sociedad tan ajetreada en la que vivimos a enseñar a los niños competencias para la vida. Los niños desarrollan su responsabilidad cuando les damos la oportunidad de aprender valiosas competencias sociales en un entorno de amabilidad, firmeza, dignidad y respeto. Es importante que sientan que los tenemos en cuenta y que son importantes para nosotros/as. 
Uno de los motivos que nos empujan a seguir abordando e investigando sobre los ambientes de aprendizajes, radica en la disminución de problemas y conflictos entre el alumnado, la disposición- acción de las maestras/os, y la cooperación y ayuda al alumnado de menor edad y sus iguales.

El hecho de tener contextos diferentes con materiales variados, novedosos, espacios en la naturaleza y de movimiento, invita al alumnado a experimentar, actuar e involucrarse en lo que quiere hacer.

El contar con alumnado de diferentes edades, les invita a ayudar, proteger y colaborar con los otros, mostrando mayor paciencia, relaciones menos bruscas y más cercanas, fomentando la empatía.

Esto sería más sencillo en escuelas con menor número de alumnado; como este centro es un C3, contamos con 9 unidades de infantil con un total de 232 alumnos/as.

Los conflictos más frecuentes que solemos encontrarnos en los ambientes son de índole diversa:

- Alumnado que destruye la producción, elaboración e interrumpe la actividad de otros compañeros/as.

- Materiales que consideran suyos y no desean compartir.

- Elevado tono de voz en algunos ambientes, ya que la emoción invita a ello.

- Dificultad en recordar algunas normas de cada ambiente.

- Desplazarse de un ambiente a otro de forma acelerada.

- Dificultad para centrarse en la actividad.

- Tratar o usar de manera inadecuada los materiales.

- Incapacidad para saber esperar en los diferentes momentos y situaciones diarias.

Al tratarse de alumnado de infantil, estas acciones serán trabajadas durante todo el ciclo, ya que en ocasiones no son continuadas en sus casas, como recoger los materiales usados, cumplir horarios y rutinas, ayudar a realizar pequeñas tareas, fomentar la autonomía. Se hace necesario una rutina continúa para que estos aprendizajes se asimilen, por ello destacamos la gran importancia que tienen las tutorías individuales, la lectura de los artículos que el profesorado de infantil irá proporcionando a la comunidad educativa, y el remar juntos para desarrollar todas las capacidades y potencialidades de cada alumno/a.

Nuestra intervención ante estas pequeñas acciones del alumnado es:

- Hablar en el momento de lo ocurrido e intentar ver sus acciones desde otra perspectiva. 
- Hablar con ellos/as en un tono tranquilo, haciéndole preguntas sobre lo que ha ocurrido y cómo se sienten. Cuando el alumnado esté ofuscado, mosqueado o indispuesto para hablar, invitarle a ir a la zona de la calma, que disponemos en cada ambiente, para que se serene y después poder comunicarnos de forma adecuada. Siempre debemos esperar a que el alumnado esté tranquilo y receptivo a interactuar, ya que no servirá de nada elevar su estado de tensión y nerviosismo.

- En aquellos espacios exteriores recurriremos a la estrategia de tiempo fuera positivo, dialogando y acompañando al alumnado en ese momento.

- Ayudarnos del reloj de las emociones para identificar y empatizar con los sentimientos y emociones vivenciados.

- Acercarnos a ellos con voz baja e indicarle alguna norma que se le haya olvidado.

- Recordarles el desplazamiento por los ambientes; si es reiterado, invitarle a volver y desplazarse de forma tranquila.

- Acompañar al alumnado que se muestra inquieto en los ambientes, invitándole a buscar un material y acompañarlo a realizar la actividad. Tenemos alumnado con NEAE que tienen una rutina de paso por los ambientes y la maestra se encarga durante el tiempo de su ambiente, de acompañarlo a interactuar con los materiales y con los demás.

- Establecer pasos por ambientes diferenciados de alumnado cuyas relaciones presenten conflictos o no inviten a mantener un adecuado estado de juego y aprendizaje en los diferentes ambientes.

- Durante los ambientes, las maestras estarán involucradas al 100\% en las relaciones del alumnado, con los materiales y sus acciones, interviniendo cuando sea necesario, pero sin imponer, intentando a través de preguntas centrar la atención del alumnado y corregir de forma amable y tranquila las acciones inadecuadas que afecten a la convivencia y al uso de los materiales.

- Destacar los momentos de relajación antes mencionados que les darán al alumnado herramientas a la hora de gestionar situaciones de enfado o rabia, regulando sus propias emociones.

Por último, en la tercera asamblea de despedida además de contar cada alumno/a en qué ambiente ha estado, o con quién, al resto de compañeros/as, la dedicamos también al trabajo de la expresión musical, corporal y rítmica, con actividades de danzas, reconocimiento de diversos sonidos, audios, instrumentos básicos de percusión cómo las claves, las panderetas, panderos, campanitas, castañuelas, tambores... y juegos diversos de ritmos corporales extraídos algunos del método BAPNE de Javier Romero. 


\section{EVALUACIÓN: OBSERVACIÓN Y ESCUCHA A NUESTRO ALUMNADO}

Nuestro gran reto educativo y pedagógico supone una nueva forma de diseñar y organizar los espacios, decidir qué tipo de materiales son los más apropiados y una forma diferente de gestionar y distribuir los tiempos en nuestra práctica diaria. Todo ello, nos lleva a concebir la evaluación como una parte importante de nuestra práctica docente. Entendemos la evaluación como un proceso de reflexión continua de todo lo que hacemos, un proceso de cuestionamiento del porqué y para qué de las cosas que hacemos, un elemento vital de creación de nuevos retos y experiencias verdaderamente significativas para todo nuestro alumnado, que les ayude a interiorizar aprendizajes y competencias para la vida. Sentimos la evaluación como un proceso formativo, de análisis constante de todo lo que hacemos, de mejora personal y profesional, que nos permita comprender y tomar decisiones encaminadas a mejorar la calidad de enseñanza que ofrecemos a nuestros alumnos/as.

La filosofía del trabajo por ambientes parte de la experimentación y el juego libre, es por eso que no se evalúan las creaciones o actividades concretas que lleva a cabo el alumnado. Es importante valorar de manera global el desempeño y evolución de los alumnos y alumnas dentro de cada espacio, la colaboración con sus compañeros y compañeras, y la adquisición de habilidades sociales. Cabe también señalar que al proporcionar diferentes espacios en los que los niños y niñas pueden mostrar sus diferentes facetas, mediante el trabajo por ambientes, los docentes obtendremos información valiosa respecto a puntos fuertes o débiles que puedan requerir refuerzo o una posible intervención.

Esta evaluación se llevará a cabo en tres momentos:

a. Evaluación inicial. Para los alumnos/as de nuevo ingreso en el centro, el tutor/a se reunirá con la familia mediante una entrevista personal para pedirles información y aspectos importantes sobre la vida de su hijo/a (datos personales, escolarización previa, cómo ha sido su desarrollo, si controla esfínteres, alergias, intolerancias, así como informes médicos o psicopedagógicos si los hubiera). Todo ello, será recogido por el tutor/a que le ayudará a tener una información relevante de su alumnado. Además, al inicio de curso cada tutor/a realizará una evaluación a su grupo para conocer el nivel inicial del que partimos (nivel de autonomía, normas, conceptos lógico-matemáticos, riqueza de vocabulario, tipo de juego que realiza...).

b. Evaluación continua. A través de la observación directa, el diario del docente, registros del alumnado por su paso por los diferentes ambientes según hemos acordado para cada trimestre (iremos recogiendo de todo el alumnado que pase por nuestro ambiente aprendizajes que van adquiriendo, cumplimiento de normas, cómo se relacionan con los demás), evidencias gráficas de algunos procesos individuales (registros trimestrales del nombre, grafía de números, esquema corporal, fotografías de procesos), etc. Cada tutor/a dispondrá de información 
suficiente para evaluar el proceso de aprendizaje que van experimentando los alumnos/as, así como los aspectos que deben trabajarse para mejorar. Además, se realizarán reuniones a lo largo de todo el curso para hablar de los procesos del alumnado y de sus interacciones: Reuniones para hablar de niños/as. Cada final de trimestre se entregará a las familias información sobre el proceso de aprendizaje de sus hijos/as. Para ello se tomarán en el aula y en los ambientes fotografías, escucha de conversaciones, etc., que ilustrarán el proceso de aprendizaje del alumnado.

c. Evaluación final. Al finalizar cada nivel (3, 4 y 5 años) el tutor/a elaborará un informe individualizado donde se recogerán datos relevantes sobre los logros y dificultades del alumnado en todo su proceso formativo. Al final de curso se realizará una entrevista individual con las familias, donde se entregarán el informe del curso con documentación, y se valorará la visión de estas en el proceso.

Durante el curso, expondremos en espacios exteriores, habilitados para ello en cada ambiente, documentaciones (poster creativo con fotos del alumnado) realizadas por cada maestra, donde mostraremos a la comunidad educativa, los procesos y vivencias que se viven en cada uno de ellos.

\subsection{Evaluación del proceso de enseñanza}

Supone una autoevaluación de nuestra práctica docente, donde evaluaremos la validez, eficacia y adecuación de la intervención con el grupo, materiales utilizados, organización de los espacios, así como las distintas actividades realizadas. Todo ello, se realizará a través del análisis y reflexión constante sobre nuestra propia práctica educativa, a través de la información recogida en nuestros registros y diarios de clase, y realizando sesiones de reflexión, debate, análisis y puestas en común con los/as compañeros/as docentes que intervienen en nuestra etapa, realizando propuestas de mejora para la futura intervención. Cada trimestre se elaborará un documento donde recojamos dificultades y propuestas de mejoras, con el fin de ir mejorando nuestra práctica docente.

Todo este proceso, supone un gran reto y una necesidad fundamental, para el buen funcionamiento de la escuela de nuestros días; será primordial que todo un equipo docente, conozca, se implique, analice y reflexione sobre cada uno/a de nuestros alumnos/as, aportando ideas y mejoras a nivel individual y grupal, con el fin de conseguir los mejores resultados en todos los aspectos.

\section{RELACIONES CON LAS FAMILIAS}

"El desarrollo integral del niño debe unir a familia y escuela" Romera (2016).

Las familias en este proyecto también son una pieza clave y fundamental del engranaje de esta maravillosa aventura. 


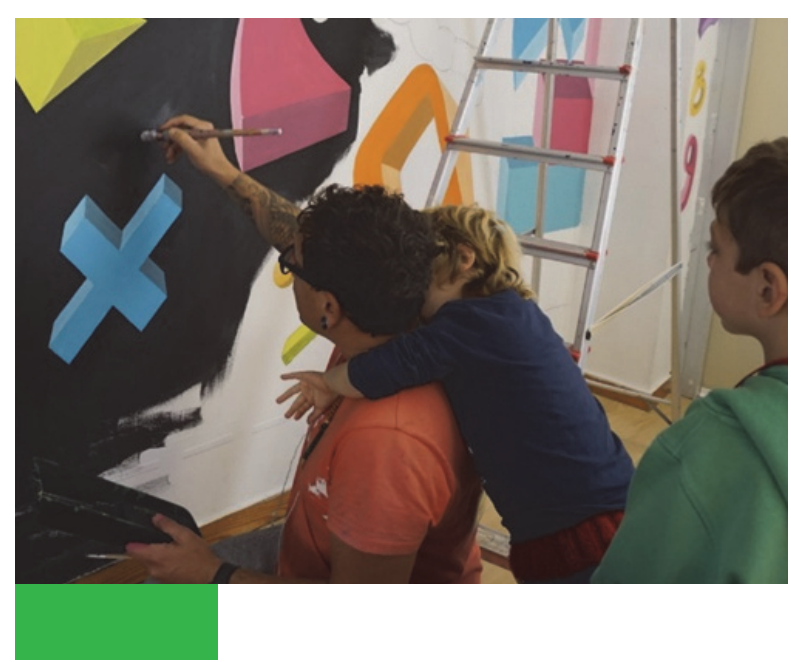

Imagen 34: Admiración

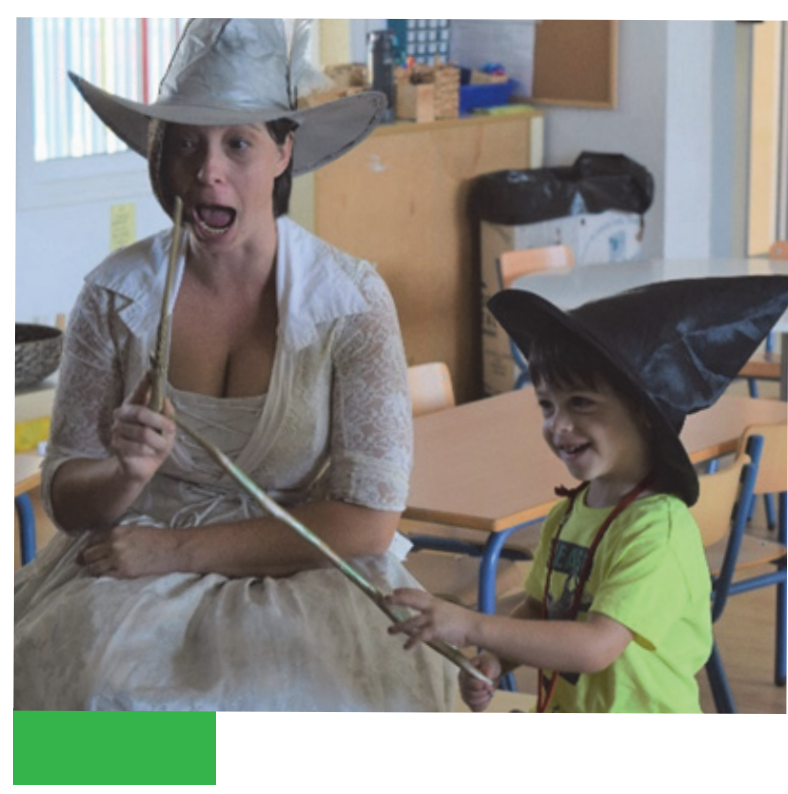

Imagen 35: ¡Sorpresa!

De forma progresiva también hemos ido observando cómo las familias del alumnado cada vez son más afines a nuestra metodología compartiendo con todo el equipo de infantil nuestras inquietudes acerca de marcar un camino hacia el protagonismo del niño/a poniéndolo en el centro del proceso de enseñanzaaprendizaje como constructor de su propio conocimiento; y, sobre todo, respetando al niño/a como un ser especial con unas características, nivel de maduración y unos intereses propios. Pensamos que es importante creer en los alumnos/as, "dejarles hacer" y guiarles hacia una progresiva autonomía y autoestima apropiada de sí mismos.

Esta muestra de confianza por parte de las familias es un hecho importante para nosotras, ya que significa un reconocimiento y una valoración hacia nuestra profesionalidad como docentes de infantil, el cual sirve de gran ayuda al ya mencionado objetivo común que ambos ámbitos, familia y escuela, perseguimos.

Además de su activa participación de forma voluntaria en la creación de espacios para embellecer las aulas, el patio o nuestro ambiente exterior, su presencia en el aula es continúa en diversas actividades de cuenta-cuentos, talleres de baile, breves exposiciones sobre sus trabajos, siendo de guías en juegos más reglados como los juegos de mesa o aportando algún tipo de material que enriquece el proceso de enseñanza-aprendizaje.

Además, las familias de educación Infantil realizan una visita al centro para celebrar el día de la familia, el 15 de mayo, donde pueden disfrutar y pasar una agradable jornada jugando en los diferentes ambientes con sus hijos, hijas, nietos, nietas, sobrinos o sobrinas.

\section{Y PARA TERMINAR...}

Nos resulta difícil explicar con palabras y en un artículo las experiencias, emociones y relaciones vividas durante este proceso que continúa transformándose y enriqueciéndose después de este recorrido. 
Sería necesario apuntar que en este tiempo no solo nosotras/os como maestras/os hemos aportado lo mejor que teníamos, sino que hemos contado con la ayuda del equipo directivo que defendió el cambio y continúa apoyando la experiencia, la comunidad educativa, sobre todo las familias, dándonos tiempo y ánimo a transformar nuestra escuela, espacios y relaciones; a la UMA, por enriquecernos con prácticas del Máster y Grado, colaborando en la preparación de algunos ambientes y permitiendo colaborar con ellos en algunas experiencias, y al Ayuntamiento, realizando algunas mejoras necesarias para desarrollar los ambientes.

Creemos y estamos convencidas que la

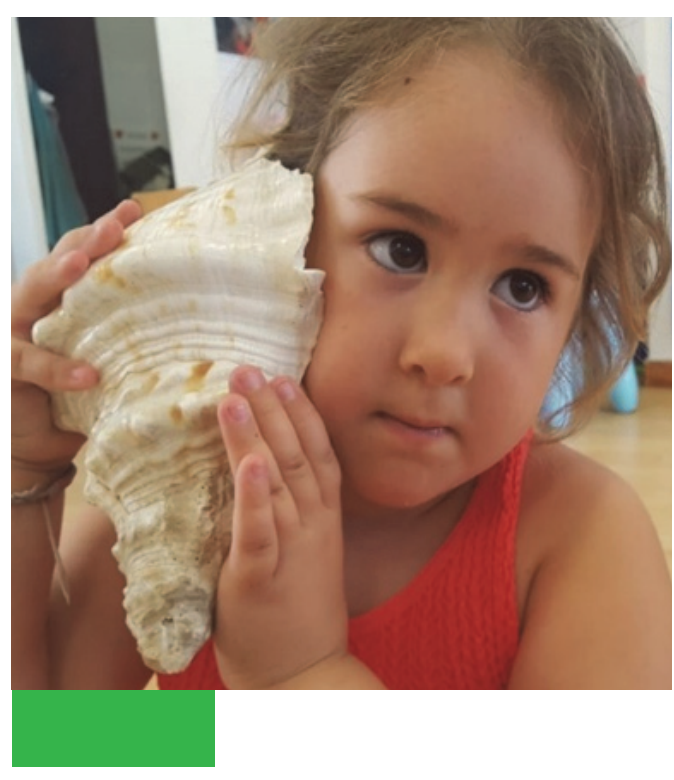

Imagen 36: ¡Magia! educación es una labor de todos/as; necesitamos maestras/os, familias e instituciones que apuesten por una educación acorde a estos tiempos, que revise sus planteamientos, que se apoye en las investigaciones neurocientíficas, que apuesten por diseñar un proyecto donde el aprendizaje de cada niño/a sea el motor de los procesos, espacios y materiales. Los niños/as necesitan que los escuchemos, que creamos en ellos, que los acompañemos permitiéndoles volar en su proceso de aprendizaje, relaciones y desarrollo de todo su ser. Continuamos reflexionando sobre nuestra práctica educativa sin perder de vista nuestro gran objetivo: Hacer una escuela que respete los tiempos, necesidades, procesos, aprendizajes y relaciones que nuestros futuros ciudadanos/as necesitan.

\section{REFERENCIAS}

BOJA (2008). Orden de 5 de agosto de 2008, por la que se desarrolla el Currículo correspondiente a la Educación Infantil en Andalucía.

Caderón, I. (2014). Educación y esperanza en las fronteras de la discapacidad. Madrid: Ediciones Cinca.

Hoyuelos, A. (2004). La ética en el pensamiento y obra pedagógica de Loris Malaguzzi. Barcelona: Octaedro-Rosa Sensat.

Mora, F. (2013). Neuroeducación. Solo se puede aprender aquello que se ama. Madrid: alianza Editorial.

Ortega, N. (2016). Entrevista recuperada de: https://bit.ly/20WtnTy

Romera, M. (2016). Entrevista recuperada de: https://bit.ly/33y19no

Teberosky, A. y Tolchinsky, L. (1989). Más allá de la alfabetización: El conocimiento fonológico, la ortografía, la composición de textos, la notación matemática y el aprendizaje. USA: Santillana Publishing Company.

Tonnucci, F. (s. f.). Entrevista recuperada de: https://bit.ly/34ANo8I

Villarroel, P. (2015). Recorrido metodológico en Ed. Inicial. Sophia, colección de Filosofía de la Educación, (9), 153-170. DOI: 10.17163/soph.n19.2015.07 